\title{
Heath care in Syria before and during the crisis
}

The Syrian International Coalition for Health (SICH) is a consortium of organizations and health professionals who are committed to improving health care and healthcare delivery in Syria. SICH was formed in 2012 in response to increasingly urgent calls for comprehensive reform. The coalition adopted five principles: Quality, equity, sustainability, broad participation and shared responsibility. Global Health Equity Foundation (GHEF), as a major contributor to human and community development worldwide, combines its core strategies of research, advocacy and capacity building to host this coalition. From administrative headquarters in Geneva, GHEF supports the SICH agenda in an equitable and neutral fashion. The coalition with its affiliates (Syrian American Medical Society, Syrian British Medical Society, Middle East Critical Care Assembly and others) along with its experts and specialists will play a major role in the Post-Conflict Needs Assessment in Syria and will evaluate the capacity and functionality of the health system to develop and implement the needed strategies and projects.

\section{Before the crisis: Baseline health status}

Health indicators improved considerably in the Syrian Arab Republic over the past three decades according to data from the Syrian Ministry of Health with life expectancy at birth increasing from 56 years in 1970 to 73.1 years in 2009; infant mortality dropped from 132 per 1000 live births in 1970 to 17.9 per 1000 in 2009; under-five mortality dropped significantly from 164 to 21.4 per 1000 live births; and maternal mortality fell from 482 per 100000 live births in 1970 to 52 in 2009. ${ }^{[1]}$ The Syrian Arab Republic was in epidemiological transition from communicable to non- communicable diseases with the latest data showing that $77 \%$ of mortalities were caused by non-communicable diseases. ${ }^{[2]}$ Total government expenditure on health as a percentage of Gross Domestic Product was 2.9 in 2009. ${ }^{[3]}$ Despite such low public investment access to health services increased dramatically since the 1980s, with rural populations achieving better equity than before. ${ }^{[1]}$

\begin{tabular}{|l|l|}
\hline \multicolumn{2}{|c|}{ Access this article online } \\
\hline Quick Response Code: & Website: \\
\hline & www.avicennajmed.com \\
\hline & \\
\hline
\end{tabular}

Despite the apparent improved capacity of the health system, a number of challenges prevail which need to be addressed to reduce inequities in access to health care and to improve the quality of care; these include, addressing validity of the data, overall inequity, lack of transparency, inadequate utilization of capacity, inadequate coordination between providers of health services, uneven distribution of human resources, high turnover of skilled staff and leadership, inadequate number of qualified nurses and allied health professionals. More recently there has been an uncontrolled and largely unregulated expansion of private providers, resulting in uneven distribution of health and medical services among geographical regions. Standardized care and quality assurance and accreditation are major issues that need to be addressed; a recent study revealed that mortality rates among critically ill patients admitted to the intensive care units with severe $2009 \mathrm{H} 1 \mathrm{~N} 1$ influenza A was $51 \%$ in Damascus compared to an APACHE II predicted mortality rate of $21 \%$ with a standardized mortality ratio of 2.4 (95\% confidence interval: $1.7-3.2, P$-value $<0.001) .{ }^{[4]}$

\section{During the crisis: Health care provision}

Syria is experiencing a protracted political and socioeconomic crisis that resulted in a severe deterioration of living conditions which has also significantly eroded the health system.

- At least 25,000 Syrians have been killed with many more were injured, among them women and children among the casualties; health staff were killed and injured while on-duty. Injuries include multiple traumas with head injuries, thorax and abdominal wounds. A Total of 192,825 refugees were registered by UNHCR as of September 7, 2012and residing in refugee camps in Turkey, Jordan, Lebanon and Iraq in addition to 53,442 refugees who are awaiting registration together with an undetermined number of displaced people who are being sheltered with host families outside Syria ${ }^{[5]}$. It is estimated that more than 2.3 million have been internally displaced; these numbers are rising by the day as the crisis is escalating very rapidly.

- Vital infrastructure has been compromised or destroyed, resulting in a lack of shelter and energy sources, deterioration of water and sanitation services, food insecurity and serious overcrowding in some areas.

- Access to health care is severely restricted, hampered by security factors. Maternal and child health services 
at the primary health care (PHC) level are disrupted. The consequences for maternal and child morbidity and mortality, among deliveries that took place during the conflict period remains unclear.

- Specific concerns remain for the chronically sick. It is estimated that more than half of those chronically ill have been forced to interrupt their treatment. These concerns are exacerbated by the virtual halt of referrals of ordinary patients outside the conflict areas as life-threatening injuries receive higher priority in an overwhelmed health care system. Elective surgery and nonurgent routine medical interventions are delayed or interrupted indicating that a growing number of patients, mainly with chronic conditions are facing a dire situation, while awaiting treatment.

- The quality of health care has been further affected by the deterioration in the functionality of medical equipment due to the lack of spare parts and maintenance shortages of drugs and medical supplies due to sanctions ${ }^{[6]}$ Routine operations are affected and many elective interventions suspended.

Very few assessments were taken place to assess the status of health care services at the conflict areas; the World Health Organization (WHO) completed a rapid assessment in late June to assess the availability and functionality of health services and resources in affected areas. The survey included 342 primary health care centers (PHC) and 38 hospitals in several affected provinces: Rural Damascus, Homs, Hama, Idleb, Der El Zor, Dara'a, and Tartous. The first six provinces were selected to assess the effect of the current unrest on health services, while Tartous was selected to assess the degree of overburdened health facilities, due to high numbers of internal refugees from other affected provinces. It was found that about $43 \%$ of PHCs are partially functioning, and $2 \%$ of PHCs are nonfunctioning, $13 \%$ PHCs are inaccessible due distance of PHC from patients ( $50 \%$, mostly in Idleb); lack of safety (34\%, mostly in Homs and Hama); difficulties in public transportation ( $8 \%$, mostly in Tartous) or temporary relocation of patients (2\%) while only $50 \%$ of hospitals are fully functioning due to lack of staff, equipment and medicine. The report showed an urgent need for infant incubators in some hospitals, CT scans, Doppler, echography, anesthesia equipment, and ambulances. Antibiotics, anti-ulcer medication, sterilizers and antidotes are also urgently needed. The major obstacles are a lack of safety related to the current situation, long distances to hospitals, and difficulties in available public transportations (12.5\%). These issues exist mainly in Rural Damascus, Daraa, Homs and Der El Zor provinces. The majority of PHCs and hospitals also count on the national water supply system as a main source of water
(88\%, 87\%, respectively). A large proportion of PHCs have no available sanitation system (mostly in Hama, Der El Zor and Dara'a). Only one-tenth of PHCs have usable generators; the majority has usable blood pressure apparatuses (94\%); Availability of nebulizers, fetoscopes and suction machines are $44 \%, 30 \%$ and $18 \%$, respectively. This assessment is limited due security issues, the dynamic situation and the rapid escalation of the crisis, it is expected the needs are at larger scale after the recent escalation in the last 2 months. ${ }^{[7]}$

There is a need for a larger assessment and evaluation of health services in the affected areas. Prompt coordinated efforts and proactive solutions of health care services for displaced people are necessary in order to mitigate the serious and negative outcomes. Multiple interventions have been attempted by the WHO in response to the crisis including the distribution of surgical kits and equipment of mobile health units in Homs and rural Damascus. ${ }^{[7]}$

\section{After the crisis: Post-conflict needs assessment}

In the postcrisis phase, there will be an urgent need for a development process designed to examine and assess the health situation in the country using a holistic approach; one that encompasses the health sector, socioeconomic status, the determinants of health, and upstream national policies and strategies that have a major bearing on health.

Post-conflict needs assessments (PCNAs) are multilateral exercises that should be undertaken by the international organizations in collaboration with the national government of Syria. The Syrian International Coalition for Health with its affiliates (Syrian American Medical Society, Syrian British Medical Society, Middle East Critical Care Assembly and others) along with its experts and specialists will play a major role in the PCNAs and in the development and implementation of strategies and needed projects. PCNAs are increasingly used by national and international actors as an entry point for conceptualizing, negotiating and financing a common shared strategy for recovery and development in fragile, post-conflict settings. The PCNA includes both the assessment of needs and the national prioritization and costing of needs in an accompanying transitional results matrix. The assessment will evaluate the capacity and functionality of the health system in addition to the following points:

- Complications and permanent disabilities for people with traumatic injuries and hearing impairment caused by explosions due to inappropriate follow-up and treatment.

- Potential risks for women who went into labor as well as infants born during the crisis period associated with 
the lack of appropriate care during labor, delivery and postpartum.

- Complications and excess mortality in patients with chronic diseases due to suspension of treatment and delayed access to health care.

- Epidemic outbreaks of water and food-borne diseases due to limited access to clean water and sanitation and a weak public health surveillance system.

- Outbreaks of vaccine-preventable diseases due to interrupted vaccination programs.

- Psychological trauma and mental health problems particularly upon children due to the effects of the conflict, ongoing insecurity and lack of protective factors.

- Deterioration of health and nutritional status leading to increasing morbidity and mortality due to a further decline in socioeconomic and security conditions and in the quality of health care.

- The extent of vulnerable groups (elderly, pregnant women, and children) or individuals who are severely affected by the emergency, having reduced coping mechanisms and limited access to appropriate services or support networks.

- The magnitude of restricted access to specialized tertiary care.

The Syrian International Coalition for health is determined within its scope and limitation to do all what it is possible not to allow a repeat of what has happened in other countries of the region, namely a total collapse of existing health infrastructure and systems.

\author{
Mazen Kherallah, Tayeb Alahfez, Zaher Sahloul, \\ Khaldoun Dia Eddin, Ghyath Jamil \\ Syrian International Coalition for Health, Global Health Equity \\ Foundation, Geneva, Switzerland \\ E-mail:mkherallah@msn.com
}

\section{REFERENCES}

1. Syrian Arab Republic, Ministry of Health Statistics, 2009, Available from: http://www.moh.gov.sy/Default.aspx?tabid=337. [Last accessed on 2012 July 29].

2. Syrian Arab Republic, Ministry of Health Statistics, 2009, Available from: http://www.who.int/nmh/countries/syr_en.pdf. [Last accessed on 2012 July 29].

3. WHO, Global health Observatory Data Repository: Available from: http: //apps.who.int/ghodata/?theme= country\# . [Last accessed 2012 July 29]

4. Alsadat R, Dakak A, Mazlooms M, Ghadhban G, Fattoom S, Betelmal I, et al. Characteristics and outcome of critically ill patients with 2009 H1N1 influenza infection in Syria. Avicenna J Med 2012;2:34-7.

5. UNHCR, Syria Regional Refugee Response: Available from: https://data.unhcr.org/syrianrefugees/download.php?id=683[Last accessed 2012 Sept 9].

6. Al Faisal W, Al Saleh Y, Sen K. Syria: Public health achievements and sanctions. Lancet 2012;379:2241.

7. Word Health Organization, regional office of Eastern Mediterranean, Situation reports for the Syrian Arab Republic. Available from: http:// www.emro.who.int/images/stories/eha/documents/Sitrep_7_for_the Web.pdf. [Last accessed on 2012 July 29].

Cite this article as: Kherallah M, Alahfez T, Sahloul Z, Eddin KD, Jamil G. Heath care in Syria before and during the crisis. Avicenna J Med 2012;2:51-3.

Announcement

\section{“QUICK RESPONSE CODE” LINK FOR FULL TEXT ARTICLES}

The journal issue has a unique new feature for reaching to the journal's website without typing a single letter. Each article on its first page has a "Quick Response Code". Using any mobile or other hand-held device with camera and GPRS/other internet source, one can reach to the full text of that particular article on the journal's website. Start a QR-code reading software (see list of free applications from http://tinyurl.com/yzlh2tc) and point the camera to the QR-code printed in the journal. It will automatically take you to the HTML full text of that article. One can also use a desktop or laptop with web camera for similar functionality. See http://tinyurl.com/2bw7fn3 or http://tinyurl.com/3ysr3me for the free applications. 